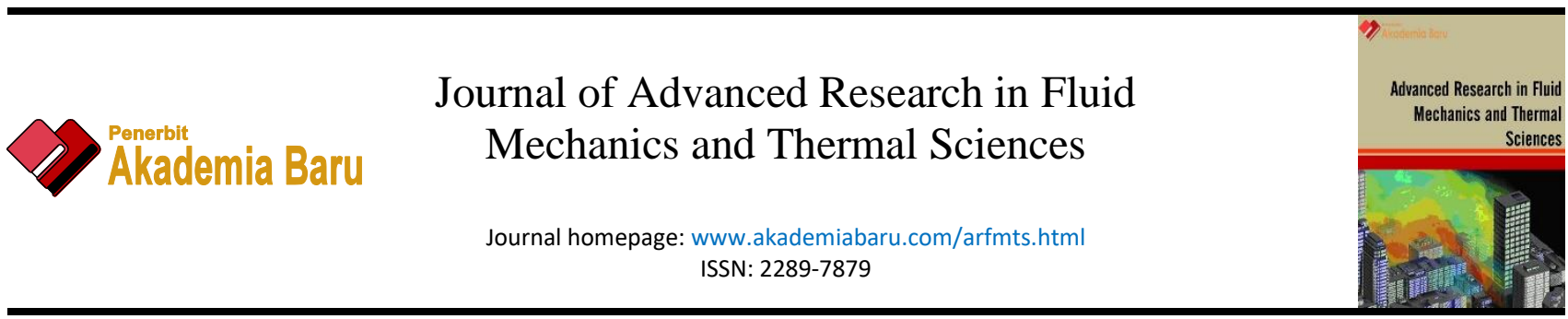

\title{
Experimental Study on Two-Phase Flow of Gas-Liquid With High Viscosity in Capillary with the Slope of $5^{\circ}$ against Horizontal Position
}

\author{
Sukamta ${ }^{1,}$, Endradi Roziantho ${ }^{1}$, Sudarja $^{1}$ \\ 1 Department of Mechanical Engineering, Faculty of Engineering, Universitas Muhammadiyah Yogyakarta, Jl. Brawijaya, Tamantirto, Kasihan, \\ Bantul, Yogyakarta, 55183, Indonesia
}

ARTICLE INFO ABSTRACT

\section{Article history:}

Received 30 December 2019

Received in revised form 14 February 2020

Accepted 16 February 2020

Available online 18 April 2020

\begin{abstract}
Two-phase flow is part of the multi-phase flow. It can occur in large, small, or mini pipes. Mini pipe two-phase flow can be applied to high-density multi-chip modules on supercomputers, X-ray equipment, high-flux heat exchangers in aerospace systems, cryogenic cooling systems on satellites, and other high-power diagnostic equipment. The more widespread application of the two-phase flow on mini pipes, so it is very needed to study its problem there. One crucial issue is increasing pressure suddenly caused by a certain flow pattern. The research was carried out using experimental methods, with an inner glass pipe diameter of $1.6 \mathrm{~mm}$ and a length of $130 \mathrm{~mm}$. The test section with a slope of 5 degrees against the horizontal position. The visualization method used a high-speed camera. The working fluid being used were air and water mixed with Glycerine with concentrations of $40 \%, 50 \%, 60 \%$, and $70 \%$ for each blend, and varying the superficial gas and water velocity in the range JG $=0.207 \mathrm{~m} / \mathrm{s}-66.3$ $\mathrm{m} / \mathrm{s} ; \mathrm{JL}=0.149 \mathrm{~m} / \mathrm{s}-4.238 \mathrm{~m} / \mathrm{s}$. The results of the videos obtained were then analyzed based on the values of JG and JL. Furthermore, they were plotted in the flow pattern maps. This research was divided into five new flow patterns: i.e., mini bubble, long plug, slug, slug-annular, and churn. The flow patterns were then compared to the previous research and indicated conformity but there was a shift in the transition line. This research also found a new invention that the slug flow pattern affected the increasing pressure difference significantly.
\end{abstract}

Keywords:

High viscosity; glycerine; mini pipe; transition line; two-phase

Copyright @ 2020 PENERBIT AKADEMIA BARU - All rights reserved

\section{Introduction}

Two-phase flow is the fluid flow that has a preliminary condition or shape or form of a different substance in a stream. It can be categorized based on its channel size, i.e., large channel, normal channel, mini-channel, microchannel, and nanochannel. Based on the channel shape (square, triangle, and circle), the channel position (vertical, horizontal, and tilt), the flow direction (concurrent

\footnotetext{
* Corresponding author.

E-mail address: sukamta@umy.ac.id (Sukamta)
} 
horizontal, counter-current horizontal, concurrent downward, concurrent upward, and countercurrent), and the formation phase (liquid-solid, solid-gas, and liquid-gas). The application of twophase flow in mini-pipe can be implemented in condensers, steam boilers, nuclear reactors, pipelines, heat exchangers, geothermal measuring devices, and natural gas searches.

Two-phase flow is the simplest phenomenon of multiphase flow. In this flow, the distribution of each phase (gas and liquid) in the channel is essential. The distribution is affected by the characteristic of flow, i.e., two-phase flow pattern and two-phase flow pattern map in the mini-channel and microchannel. The fluid has a unique characteristic, i.e., its surface tension is so dominant that Newton's laws cannot be implemented. The small channel diameter causes the occurrences of this phenomenon. As a consequence, the flow pattern formed is only influenced by the surface tension and the viscosity of the liquid fluid, and the value of the superficial velocity of the gas and the liquid fluid.

Triplett et al., [1] conducted research by using air and water in circular microchannel pipes with a diameter of 1.1 and $1.45 \mathrm{~mm}$, and also in semi-triangular microchannel pipes of 1.09 and $1.49 \mathrm{~mm}$ in diameter. The variation of superficial gas velocity (JG) started from $0.02-80 \mathrm{~m} / \mathrm{s}$, and the superficial liquid velocity (JL) was from $0.02-8 \mathrm{~m} / \mathrm{s}$. The occurred flow patterns were bubbly, slug, slug-annular, annular, and churn. A flow pattern of stratified was found in the study because of the influence of massive surface tension. Chung and Kawaji [2] studied the effect of channel diameter on the characteristic of adiabatic two-phase flow in a microchannel. In their study, the used fluids were nitrogen gas and water in the channel with a diameter of 530, 250,100, and $50 \mu \mathrm{m}$. The used superficial liquid velocity ranged from $0.01-5.77 \mathrm{~m} / \mathrm{s}$ while the superficial gas velocity reached $0.02-$ $72.98 \mathrm{~m} / \mathrm{s}$. The used visualization method was a photographic image. The results of visualization showed the difference between the flow pattern in the 530 and $250 \mu \mathrm{m}$ diameter pipes with 100 and $50 \mu \mathrm{m}$ diameter pipes. The flow patterns observed in this study, with a diameter of 530 and $250 \mu \mathrm{m}$, were bubbly, slug, churn, slug-annular, and annular. Whereas in the 100 and $50 \mu \mathrm{m}$ diameter pipes, the observed flow pattern was a slug. Liu D. and Sur A. [3] studied the water-air two-phase flow in circular flow with a diameter of 100,180, and $324 \mu \mathrm{m}$. In the study, four flow patterns were formed, i.e., bubbly, slug, ring, and annular. The bubbly flow has a characteristic of the dispersed bubble single-flow pattern with a smaller size of diameter compared to the channel size. The slug flow has a characteristic as the circuit from Taylor Bubble, which is elongated and separated by a lump of water. Annular flow has a characteristic of a flow of gas that flows continuously at the center of the channel, forming a gas core surrounded by a film layer with a form of the ring like a neck around it. Annular flow is a continuous flow of gas at the center of the channel, forming a gas core surrounded by a stable layer of water.

Sudarja et al., [4] conducted research on the effect of viscosity in gas-liquid two-phase flow in the horizontal mini-channel. The used test section was a glass pipe with a diameter of $1.6 \mathrm{~mm}$ with a superficial gas velocity of $0.025-66.3 \mathrm{~m} / \mathrm{s}$, and superficial velocity of the fluid of $0.033-4.935 \mathrm{~m} / \mathrm{s}$. The used liquid was air and a mixture of distilled water-glycerine with a percentage of $0 \%, 20 \%$, $40 \%$, and $60 \%$, and indices of $\mathrm{W}, \mathrm{G} 20, \mathrm{G} 40$, and G60. The flow pattern data were obtained by analyzing video images and captured by using a high-speed camera. The results revealed that the flow patterns were bubbly, plug, slug-annular, annular, and churn, while a stratified flow was not found. Two-phase flow in mini-pipes and micropipes have been applied and continued to be developed rapidly in two fields, namely Micro-Electro-Mechanical System (MEMS, miniaturization of mechanical and electromechanical elements) and also in the flow in the structure of the human body. Two-phase flow in the mini-pipe can be applied in high-density multi-chip modules on supercomputers, X-ray equipment and other high-power diagnostic equipment, and high-flux heat exchangers in aerospace systems, as well as cryogenic cooling systems on satellites [5]. 
Korawan [6] studied a two-phase flow pattern (water and air) in a horizontal pipe with the superficial water velocity variations (USL) of $0.4,0.55,0.7,0.85$, and $1.0 \mathrm{~m} / \mathrm{s}$. The research was conducted by using a test module made of acrylic pipe with an inner diameter of $36 \mathrm{~mm}$ and a length of $2000 \mathrm{~mm}$. The liquid fluid was in the form of water, whereas the gas fluid was in the form of air. The used method was by flowing water pumped from the tank to the flow meter and then to the injector. The air was supplied from the compressor and flowed through rota-meter to the injector. The water-air mixed in the injector flowed through the test module to the separator. In the separator, the air was released into the atmosphere, and the water would flow into the tank to be circulated again. A digital camera was used to obtain pictures of the flow patterns. The results showed that the flow patterns were bubbly, slug, and stratified flow. The higher the value of USL, the longer the bubble region that occurred. Also, the higher the USL value led to the shift in changes in flow patterns. When the USL is low, bubble flow changed to be stratified flow, whereas when the USL was high, bubble flow changed to slug flow. The determination of sub-stratified water-air flow patterns in horizontal pipes using pressure measurements has been studied [7]. The purpose was to classify the sub-stratified water-air flow patterns in horizontal pipes based on the result of measuring the pressure sensor output signal. The method used in the study was the experimental study, visualization, and measurement of pressure difference fluctuations. The tool was a transparent acrylic pipe with a diameter of $26 \mathrm{~mm}$ and a length of $10 \mathrm{~m}$. A high-speed camera was used to obtain visualization of sub-stratified flow patterns. The study utilized a test section with 180 and 210D tap positions to measure pressure difference fluctuations. The study revealed that the stratified flow pattern that could be visually observed was divided into sub-regions which included stratified smooth $(\mathrm{JL}=0.025 \mathrm{~m} / \mathrm{s}$ and $\mathrm{JG}=1.88 \mathrm{~m} / \mathrm{s})$, two dimensional wave $(\mathrm{JL}=0.025 \mathrm{~m} / \mathrm{s}$ and $\mathrm{JG}=3.77 \mathrm{~m} / \mathrm{s})$, roll wave $(\mathrm{JL}=0.05 \mathrm{~m} / \mathrm{s}$ and $\mathrm{JG}=3.77 \mathrm{~m} / \mathrm{s})$, and atomization $(\mathrm{JL}=0.075 \mathrm{~m} / \mathrm{s}$ and $\mathrm{JG}=3.77 \mathrm{~m} / \mathrm{s})$. Aqli and Adhika [8] also conducted an experimental study on two-phase flow patterns in the mini-channel superficial velocity of gases and liquids respectively in the range of $0.025-66,300 \mathrm{~m} / \mathrm{s}$ and 0.033 $4,935 \mathrm{~m} / \mathrm{s}$. This study found a flow pattern of bubbly, plug, slug-annular, annular, and churn flow. These results are consistent with the results of the study of Triplett et al., [9] and Chung and Kawaji [2]. Previous studies were carried out on two-phase gas-liquid flow in a micro-channel width of 5-20 $\mu \mathrm{m}$ using the Boltzmann method. This research looks at the dynamic behavior that continuously from bubbles and droplets. This study found that the wetting of solid walls determines the shape of bubbles in the slug flow. Also, the shape and number of bubbles under steady-state is influenced by surface tension, viscous force, and inertia. Meanwhile, the simulation results show that the steadystate flow regime is very dependent on the viscous force, surface tension, inertia force, channel width, and solid surface wetting [10]. Meanwhile, the previous study also observes the two-phase gas-liquid flow pattern accompanied by chemical reactions in $400 \mu \mathrm{m}$ square microchannel using a high-speed camera and pressure sensor. This study found a slug-bubbly flow, slug flow, and slugannular flow [11].

An experimental study to characterize air-water flow in pipes with a diameter of $3.81 \mathrm{~cm}$ has been carried out. This study uses a high-speed camera to verify the map of the previous flow regime. The two-phase flow is classified into bubbly, plug, slug, stratified, stratified-wavy, and annular flow regimes. While the transition boundaries identified in this study compared to previous studies include Mandhane et al., [21] and Talley et al., [22]. The effects of increasing the gas flow rate on the void fraction, the average diameter of the bubble, and the speed of the bubble are discussed. Bubbles start to coalesce near the gas-liquid layer instead of in very dense areas because of the gas flow rate increases [12]. Previous research has also studied the behavior of two-phase flow in rectangular channels with varying air/water flow rates. Experimental data were recorded using pressure transducers and water-air flow behavior was visualized with a camcorder for airflow rates of 8.3, 
16.6, and $25 \mathrm{~L} / \mathrm{min}$ and water flow rates that differed from 5, 10, 15 and $20 \mathrm{~L} / \mathrm{min}$. The results showed that by increasing the value of water or airflow rates, the shape, size, and number of air bubbles in the water changed accordingly. Higher water flow rates cause the flow to be very turbulent and foamy [13]. The phenomenon of liquid carryover at the T-junction has been analyzed using Volume Faction together with the $k-\varepsilon$ turbulence model. The efficiency of T-junction separation is measured through the fraction of air and water mass flow rates between branches and main arms at a diameter ratio of 0.6-1.0, surface water velocity of $0.186-0.558 \mathrm{~m} / \mathrm{s}$ and air-surface velocity of 4$8 \mathrm{~m} / \mathrm{s}$. The results show that the simulation model has been successfully validated with an average deviation of less than $5 \%$ and can be used to predict the phase separation of the snail flow at the Tjunction. In the slug flow regime, the performance of the T-junction can be improved by reducing airspeed or increasing water speed [14].

The information and data on the study of two-phase flow pattern and flow pattern map in the mini pipe with the variation of the slope, surface tension, and liquid viscosity are minimal. Therefore, an experimental and numeric study needs to be carried out to complete the previous studies. This study tests the variation of liquid fluid viscosity with a mixture of water and glycerine. This study aims to compare the flow pattern and flow pattern map toward the variety of slope and the superficial gas velocity.

\section{Methods}

The installation of equipment used in the research is shown in Figure 1. The equipment consists of the main components, namely water tank, water pump, air compressor, pressure vessel, test section (inner diameter of $1.6 \mathrm{~mm}$, length of $130 \mathrm{~mm}$ ), water trap, mixer, and connector. Supporting equipment used in research includes amplifiers, optical correction boxes, cameras, computers, video processing systems, and acquisition systems. The working fluid was used air-water mixed by glycerine with a concentration of $40 \%$ (GL40), 50\% (GL50), 60\% (GL60), 70\% (GL70). The used measuring instruments include a water flow meter, airflow meter, temperature indicator, thermocouple, pressure indicator, and pressure transducer. For streaming video shooting, a high-speed camera Nikon type $\mathrm{J} 4$ was used, with a speed of $1200 \mathrm{fps}$ and a resolution of $640 \times 480$ pixels. Data acquisition from "National Instrument" was used to convert data from analog to digital so that it could be recorded, stored, processed, and analyzed on a computer. The condition of the study was adiabatic. Experiments were carried out at superficial gas velocity (JG) at intervals of $0.149-66.3 \mathrm{~m} / \mathrm{s}$, and superficial liquid velocity (JL) at intervals of $0.149 \mathrm{~m} / \mathrm{s}-4.238 \mathrm{~m} / \mathrm{s}$. 


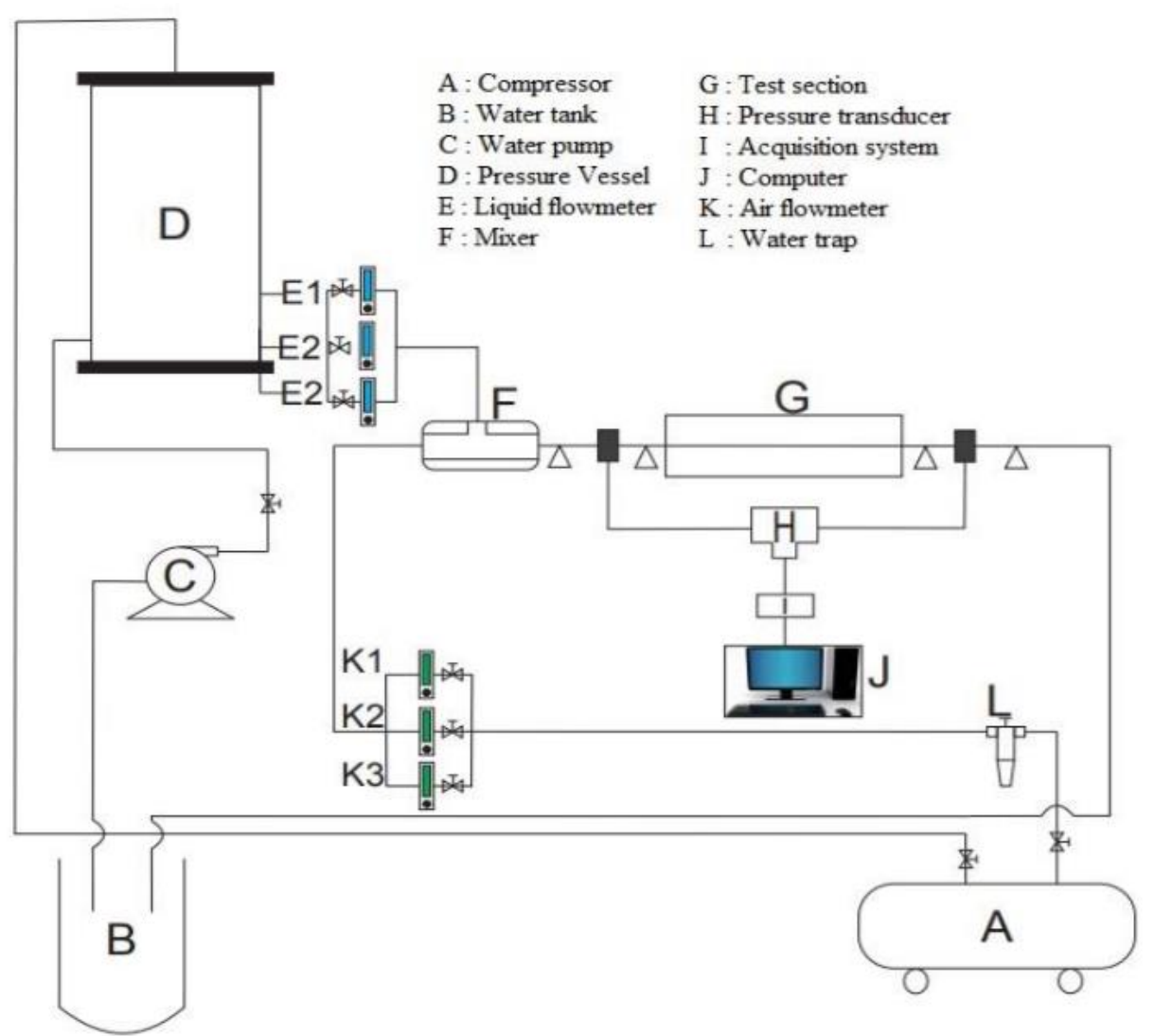

Fig. 1. The installation of equipment

\section{Results and Discussion}

These results document several key contributions made to the fields of two-phase flow in a mini channel. Bubbly flow pattern was formed at low JG and high JL as shown in Figure 2. In this case, solution discharge would flow to meet the mixing chamber while the low airflow would break through the dominating volume of solution in the mixing chamber. As the air volume increased and reduced the mixing chamber's surface area to the $1.6 \mathrm{~mm}$ inner diameter pipe, the air would try to push the solution and cause a two-phase flow to form on the mini channel. The value of the surface tension of the solution affected the airflow as if it was cut into small bubbles.

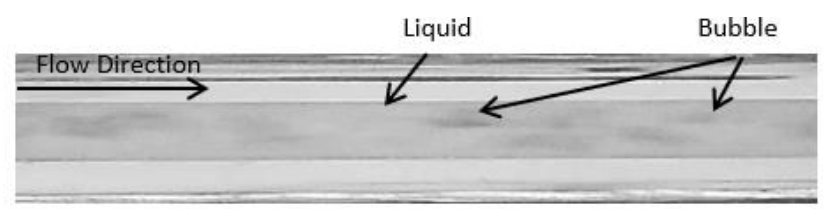

(a)

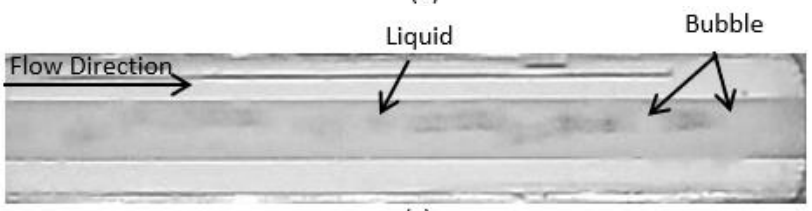

(c)

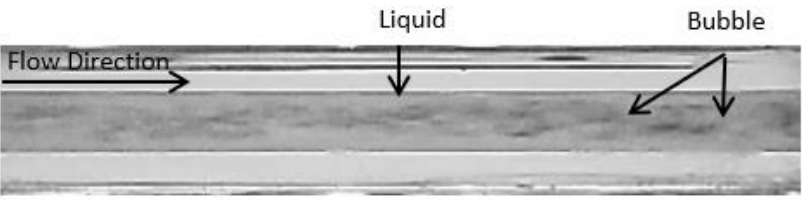

(b)

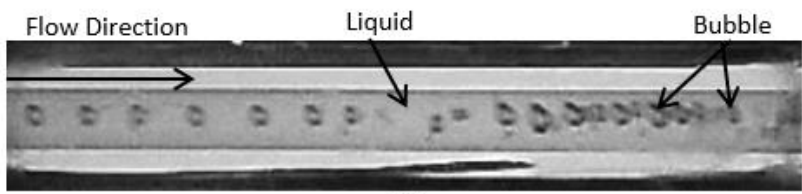

(d)

Fig. 2. The bubbly flow pattern formed on JG $=0.871 \mathrm{~m} / \mathrm{s}$ and JL $=2,297 \mathrm{~m} / \mathrm{s}$ (a) $G L 40$, (b) $G L 50$, (c) GL60, (d) GL70 
Plug flow pattern was formed at low JG and JL as shown in Figure 3. This pattern was an elongated bubbly flow pattern with a more significant length than the diameter of the pipe. The bubble extension was due to the increase in air intensity in the flow. The shape of the plug flow pattern was like a capsule or bullet of varying lengths. The plug flow pattern occurred regularly and consistently at the beginning of JG and JL, but as the superficial velocity increased, the shape of the plug flow pattern would change. This flow pattern was a substitute for the stratified flow pattern formed in conventional pipes. In mini-pipes, the effect of capillary forces caused no stratified flow pattern to emerge. When the solution level in the mixing chamber began to increase and prepared to enter the channel along with the airflow, the capillary force of the liquid would form a liquid bridge, which was the initial formation of the plug flow pattern.

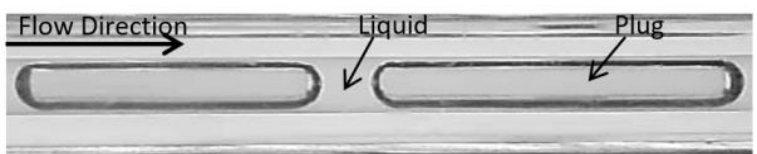

(a)

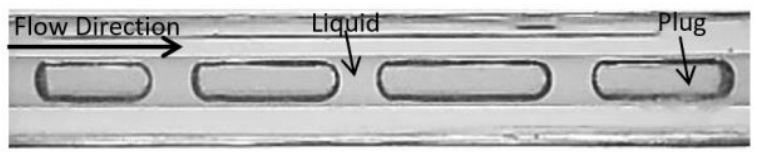

(c)

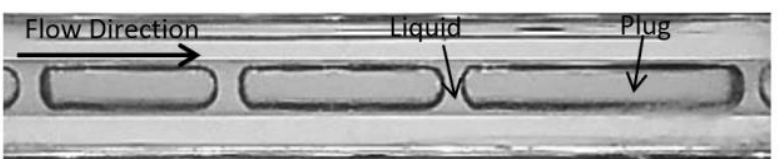

(b)

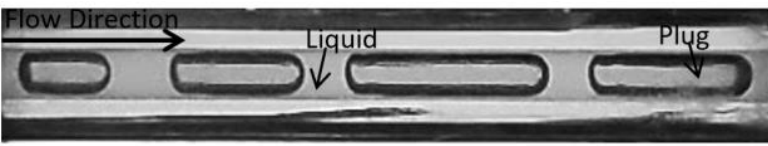

(d)

Fig. 3. Comparison of the length of plug flow patterns for each condition of the glycerinee concentration solution at JG $=0.207 \mathrm{~m} / \mathrm{s}$ and JL $=0.149 \mathrm{~m} / \mathrm{s}$ (a) GL40, (b) GL50, (c) GL60, (d) GL70

The slug-annular flow pattern was the flow pattern transition from a plug flow pattern to an annular flow pattern. The slug-annular flow pattern occurred when the airflow had flowed continuously. Meanwhile, the flow of liquid fluid tried to penetrate the airflow that appeared around it. Also, in a liquid, the layer at the bottom was thicker than that at the top.

Furthermore, under certain conditions, the liquid fluid layer at the bottom increasingly thickened and formed waves. The slug-annular flow pattern was formed because the layer of water at the bottom was thicker compared to that at the top. Frothy bubbly was often obtained in this flow pattern, and it could break at any time. This result led to the formation of waves in the solution or made the airbag cut and formed a plug flow pattern. The increase of the viscosity of the liquid caused the thickening of the water layer around the air stream. The layer was moving continuously and occasionally experienced interference in the form of water waves that wanted to break the airflow rate. A comparison of slug-annular flow patterns with the same JG and JL values and the varied glycerine concentration can be seen in Figure 4.

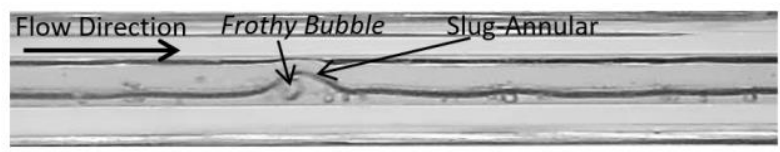

(a)

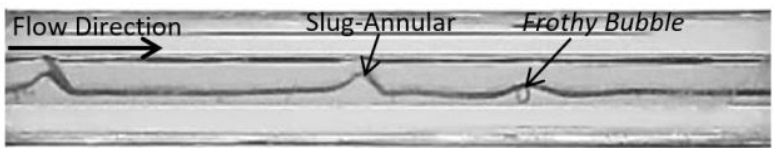

(c)

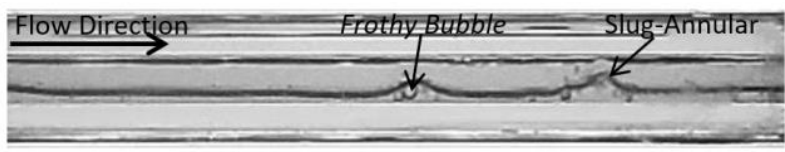

(b)

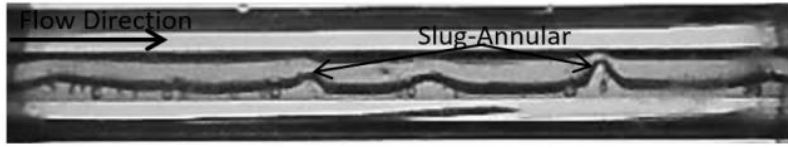

(d)

Fig. 4. Comparison of slug-annular flow patterns in various conditions of glycerine concentration with JG $=4.238 \mathrm{~m} / \mathrm{s}$ and JL $=0.149 \mathrm{~m} / \mathrm{s}$ (a) GL40, (b) GL50, (c) GL60, (d) GL70 
The annular flow pattern (Figure 5) was a continuation of the slug-annular flow pattern of which the superficial velocity of the gas continuously increased to the maximum extent. It caused the waves that tried to pass the airflow. As a consequence, a flow pattern was formed, i.e., an airflow that flowed continuously with a liquid layer and little ripples stream alongside. The thickness of the top layer and the bottom layer had no significant differences. Therefore, this flow was usually called a 'ring' flow. When it was viewed from the front, a solution would appear. It seemed to encircle the core of the air as if it was forming a ring.

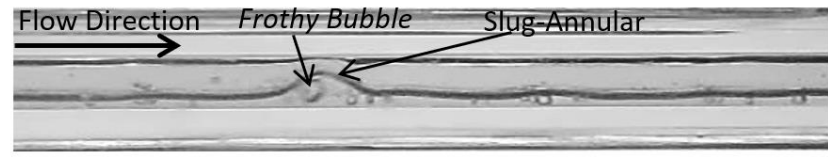

(a)

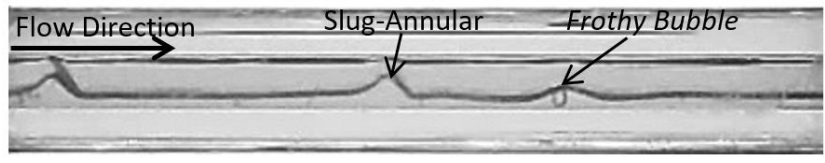

(c)

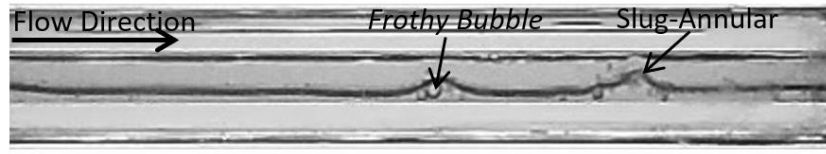

(b)

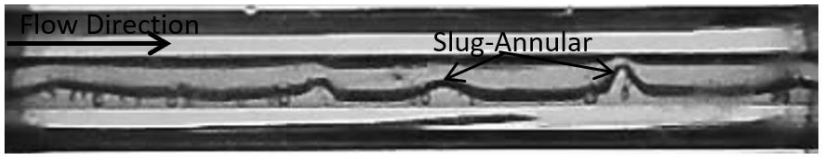

(d)

Fig. 5. Comparison of annular flow patterns in various conditions of glycerine and the concentration of JG $=66.3 \mathrm{~m} / \mathrm{s}$ and JL $=0.539 \mathrm{~m} / \mathrm{s}$ (a) GL40, (b) GL50, (c) GL60, (d) GL70

Churn flow pattern (Figure 6) occurred at a high superficial velocity of air and liquid, then the core of air and liquid became disordered. The increase of air and liquid volume in slug-annular and annular flow patterns caused the liquid layer on the pipe wall growing thicker. The previous airflow pattern which streamed continuously was interrupted by huge liquid volume. The amount of the volume of the flow solution should be able to form a slug flow pattern, but the large air velocity made the solution dispersed into a tiny size and flowed at high speed. As a consequence, in the observation, only black shadows were visible in the air core flow, which was enveloped by the flow of liquid fluid that flowed quickly.

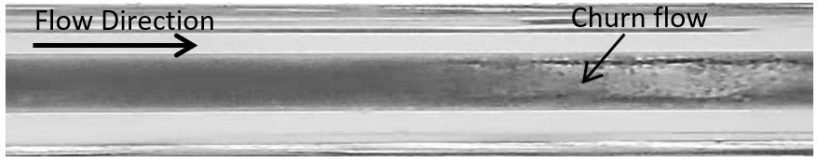

(a)

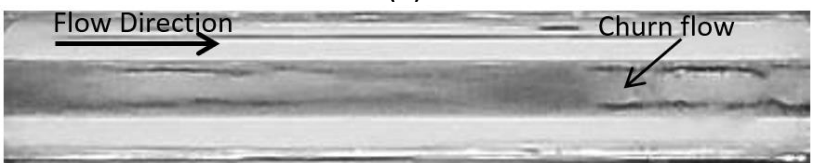

(c)

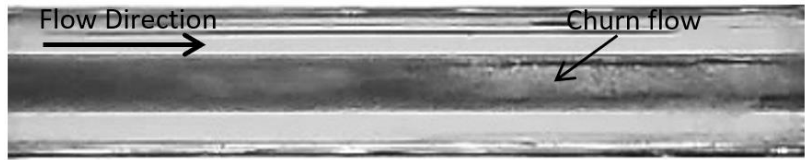

(b)

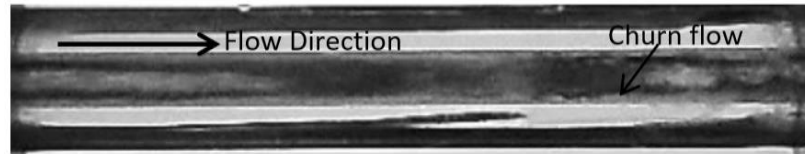

(d)

Fig. 6. Comparison of churn flow patterns in various conditions of glycerine concentration with JG $=22.6$ $\mathrm{m} / \mathrm{s}$ and $\mathrm{JL}=2.297 \mathrm{~m} / \mathrm{s}$ (a) GL40, (b) GL50, (c) GL60, (d) GL70

A comparison between the results of this study and previous research is needed to determine the consistency of the results obtained, and changes in results in the transition line caused by changes in the specific parameters tested. A comparison of flow pattern maps with changes in viscosity and slope angle is done using the results of the study of Triplett et al., [9]. Figure 7 shows some differences in the transition lines. The transition lines between churn, slug-annular, and annular flow patterns are shifting. This phenomenon is caused by differences in the viscosity of the liquid fluid and the pipe diameter. The liquid in this study is a mixture of water and glycerin with concentrations of 40,50,60, and $70 \%$ and a diameter of $1.6 \mathrm{~mm}$ pipe. Meanwhile, in the study of Triplett et al., [9], the liquid used 
is water with a pipe diameter of $1,097 \mathrm{~mm}$. A review of the analysis of the factors affecting the regime boundaries of the two phases of the bubble, slug, and annular flow in different cross-sections of the mini channel has been carried out. The analysis involves the main parameters that affect the structure of the two-phase flow, namely the superficial velocity of the gas and liquid flow, the dimensions of the channel, the wetness of the inner surface of the channel, the liquid nature, and the gravitational force. It can be concluded that the development of two-phase flow instability has a significant impact on the formation, evolution, and change of flow regimes [15]. Previously, an experimental study of two-phase gas-liquid adiabatic flow patterns in a horizontal mini channel has also been conducted. This research uses a $1.6 \mathrm{~mm}$ inner diameter pipe. Working fluid uses air and water mixed with glycerol $0 \%, 20 \%, 40 \%$, and $60 \%$. It was found that changes in fluid viscosity affect the shifting of transition lines between flow patterns, especially slug-annular to annular and slugannular and annular to churn flow [16].

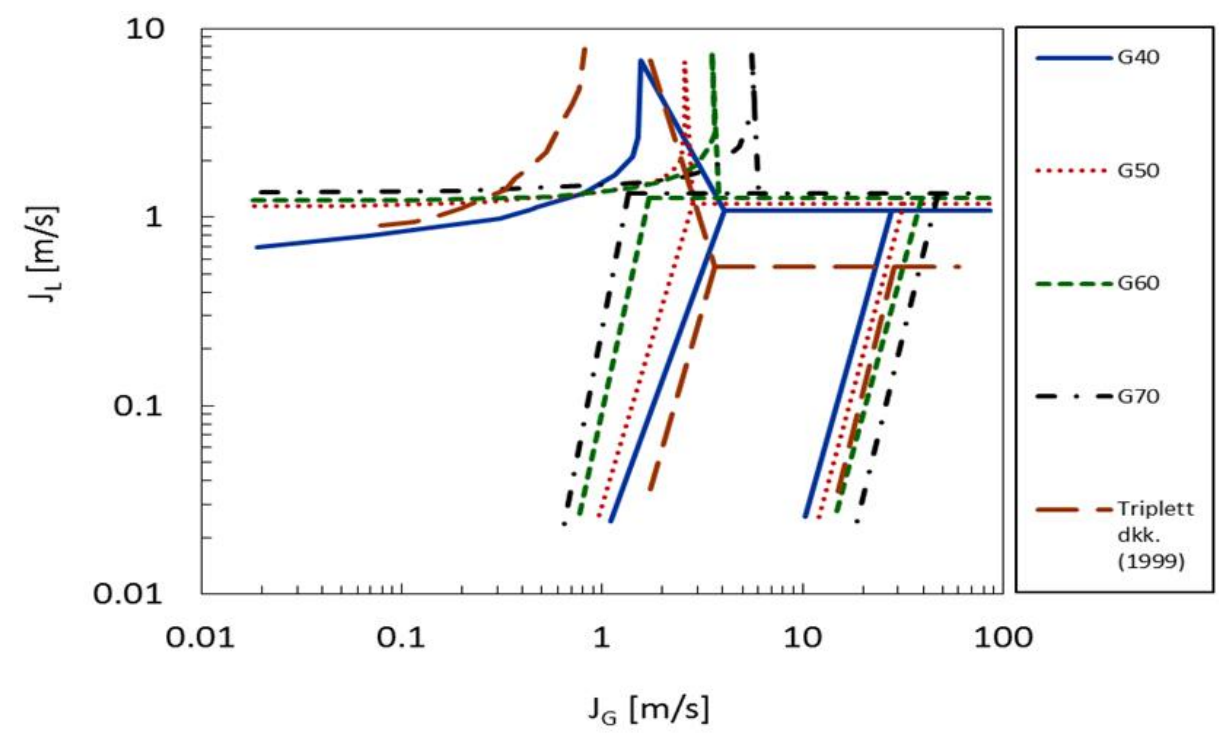

Fig. 7. Comparison between the transition patterns of flow pattern maps in this study and those in Triplett et al., [9]

Previous papers have clearly demonstrated that there is a good fit between simulation and experimental data for slug-annular, annular and churn flow patterns. This research also clearly explains that fluid viscosity also has a significant impact on the pressure gradient, where the pressure gradient affects the flow pattern. So, the previous paper supports the new findings in this research [17]. On the other hand, The characteristics of two-phase water-air flow patterns in mini-square channels were investigated experimentally using channels made of permeable porous media. The flow patterns of this particular two-phase gas-liquid flow have been cataloged, and the effects of gas flow rates and liquid infiltration rates on flow patterns are also analyzed. The results show that the differential pressure is affected by the amount of liquid infiltration and the gas flow rate which increases significantly [18].

Meanwhile, An experimental two-phase flow study on the microchannel using propane working fluid on a microchannel with a diameter of $500 \mu \mathrm{m}$ and a length of $0.5 \mathrm{~m}$ has also been carried out. The research variables are mass flux 360 to $915 \mathrm{~kg} / \mathrm{m} 2 \mathrm{~s}$ and vapor quality from 0 to unity. Homogeneous and separate models are used to determine the decrease in friction pressure in twophase flow. Several correlations exist of the two-phase flow viscosity and density used to predict the decrease in friction pressure [19]. Previous studies present analytic models for the calculation of twophase pressure drops for homogeneous separate flows. This study uses four different refrigerant 
variables, vapor quality, inner tube diameter, and mass flux at saturated temperature, to test the pressure drop model [20]. The results showed good appropriate with previous studies on the behavior of two-phase pressure gradient. These findings contribute to the design of heat exchangers, especially in small diameters.

\section{Conclusion}

This research resulted in new findings related to five types of the bubble, plug, slug-annular, annular, and churn flow patterns. The plug-annular flow pattern is formed due to an increase in the superficial velocity of the gas in the plug flow. With the increase in gas velocity, the liquid waves that occur in the lower layer will decrease and spread around the airflow to form an annular flow pattern. Churn flow patterns are formed when the velocity of gas and liquid is very high. Increased viscosity has a significant effect on flow patterns especially for bubbly and plugs flow patterns. The higher the viscosity value, the more regular the bubble flow patterns are formed, and the dispersed bubbles will decrease. Meanwhile, in the plug flow pattern, the effect of increasing the viscosity value causes the plug to be shorter. The results of the comparison of flow pattern maps with previous studies show good suitability.

\section{Acknowledgement}

Thanks to the Ministry of Higher Education, Research and Technology of Republic Indonesia supported this research with contract no. 111/SP2H/LT/DRPM/2019.

\section{References}

[1] Triplett, K. A., S. M. Ghiaasiaan, S. I. Abdel-Khalik, A. LeMouel, and B. N. McCord. "Gas-liquid two-phase flow in microchannels: part II: void fraction and pressure drop." International Journal of Multiphase Flow 25, no. 3 (1999): 395-410.

https://doi.org/10.1016/S0301-9322(98)00055-X

[2] Chung, PM-Y., and M. Kawaji. "The effect of channel diameter on adiabatic two-phase flow characteristics in microchannels." International Journal of Multiphase Flow 30, no. 7-8 (2004): 735-761.

https://doi.org/10.1016/i.ijmultiphaseflow.2004.05.002

[3] Sur, Aritra, and Dong Liu. "Adiabatic air-water two-phase flow in circular microchannels." International Journal of Thermal Sciences 53 (2012): 18-34.

https://doi.org/10.1016/i.ijthermalsci.2011.09.021

[4] Sudarja, Jayadi, Deendarlianto Indarto, and Adhika Widyaparaga. "The effect of liquid viscosity on the gas-liquid two-phase flow pattern in horizontal mini-channel." In American Institute of Physics Conference Series, vol. 2001, no. 3. 2018. https://doi.org/10.1063/1.5049982

[5] Bi, Q. C., and T. S. Zhao. "Taylor bubbles in miniaturized circular and noncircular channels." International Journal of Multiphase Flow 27, no. 3 (2001): 561-570.

https://doi.org/10.1016/S0301-9322(00)00027-6

[6] Korawan, Agus Dwi. "Pola Aliran Dua Fase (Air+ Udara) pada Pipa Horisontal dengan Variasi Kecepatan Superfisial Air." Mekanika 14, no. 1 (2015).

[7] Banjarbaru, Gedung Fakultas Teknik Unlam, and Akhmad Syarief. Proceeding Seminar Nasional Tahunan Teknik Mesin XIV (SNTTM XIV). Badan Kerjasama Teknik Mesin (BKSTM) Indonesia Universitas Lambung Mangkurat Banjarmasin, 2015.

[8] Haq, Aqli, and Adhika Widyaparaga. "Experimental study on the flow pattern and pressure gradient of air-water two-phase flow in a horizontal circular mini-channel." Journal of Hydrodynamics 31, no. 1 (2019): 102-116. https://doi.org/10.1007/s42241-018-0126-2

[9] Triplett, Ka A., S. M. Ghiaasiaan, S. I. Abdel-Khalik, and D. L. Sadowski. "Gas-liquid two-phase flow in microchannels Part I: two-phase flow patterns." International Journal of Multiphase Flow 25, no. 3 (1999): 377-394. https://doi.org/10.1016/S0301-9322(98)00054-8

[10] Lou, Qin, Mo Yang, and Hongtao Xu. "Numerical investigations of gas-liquid two-phase flows in microchannels." 
Proceedings of the Institution of Mechanical Engineers, Part C: Journal of Mechanical Engineering Science 232, no. 3 (2018): 466-476.

https://doi.org/10.1177/0954406217740928

[11] Yin, Yaran, Chunying Zhu, Rongwei Guo, Taotao Fu, and Youguang Ma. "Gas-liquid two-phase flow in a square microchannel with chemical mass transfer: Flow pattern, void fraction and frictional pressure drop." International Journal of Heat and Mass Transfer 127 (2018): 484-496. https://doi.org/10.1016/j.ijheatmasstransfer.2018.07.113

[12] Kong, Ran, and Seungjin Kim. "Characterization of horizontal air-water two-phase flow." Nuclear Engineering and Design 312 (2017): 266-276.

https://doi.org/10.1016/i.nucengdes.2016.06.016

[13] Radhi, Dhuha, Ali Mohammed Hussein Mohsen, and Ammar Abdulkadhim. "Experimental Investigation of Twophase Fluid Flow over a Rectangular Obstructions Located Inside Enlarged Rectangular Channel Experimental Investigation of Two-phase Fluid Flow over a Rectangular Obstructions Located Inside Enlarged Rectangular Channel." Mathematical Modelling of Engineering Problems 6, no. 2 (2019): 183-187. https://doi.org/10.18280/mmep.060205

[14] Tran, Minh, Zeeshan Memon, Ahmed Saieed, William Pao, and Fakhruldin Hashim. "Numerical simulation of twophase separation in T-junction with experimental validation." Journal of Mechanical Engineering and Sciences 12, no. 4 (2018): 4216-4230.

[15] Chinnov, E. A., F. V. Ron'Shin, and Oleg Alexandrovich Kabov. "Regimes of two-phase flow in micro-and minichannels." Thermophysics and Aeromechanics 22, no. 3 (2015): 265-284. https://doi.org/10.1134/S0869864315030014

[16] Sudarja, Farid Jayadi, Indarto, Deendarlianto, and Adhika Widyaparaga. "The effect of liquid viscosity on the gasliquid two-phase flow pattern in horizontal mini-channel." In AIP Conference Proceedings, vol. 2001, no. 1, p. 030010. AIP Publishing LLC, 2018. https://doi.org/10.1063/1.5049982

[17] Sukamta, Sukamta. "Computational Fluid Dynamics (CFD) and Experimental study of Two-Phase Flow Patterns GasLiquid with Low Viscosity in a Horizontal Capillary Pipe." CFD Letters 11, no. 8 (2019): 16-23.

[18] Li, Jian, Jun Zhao, and Shixue Wang. "Gas-liquid two-phase flow in a mini-channel with water infiltration continuously along the flow direction." International Journal of Green Energy 12, no. 3 (2015): 207-214. https://doi.org/10.1080/15435075.2014.891521

[19] Novianto, S., Agus Sunjarianto Pamitran, R. Koestoer, and K. Saito. "Two-phase frictional pressure drop of propane with prediction methods of viscosity and density in $500 \mu \mathrm{m}$ diameter tube." In IOP Conference Series: Materials Science and Engineering, vol. 316, no. 1, p. 012058. IOP Publishing, 2018. https://doi.org/10.1088/1757-899X/316/1/012058

[20] Morad, Akeel Mohammed Ali. "A Two-Phase Pressure Drop Model for Homogenous Separated Flow for Circular Tube Condenser, Examined with Four Modern Refrigerants." Journal of Advanced Research in Fluid Mechanics and Thermal Sciences 52, no. 2 (2018): 274-287.

[21] Mandhane, J. M., G. A. Gregory, and K. Aziz. "A flow pattern map for gas-liquid flow in horizontal pipes." International Journal of Multiphase Flow 1, no. 4 (1974): 537-553. https://doi.org/10.1016/0301-9322(74)90006-8

[22] Talley, Justin D., Ted Worosz, Seungjin Kim, and John R. Buchanan Jr. "Characterization of horizontal air-water twophase flow in a round pipe part I: Flow visualization." International Journal of Multiphase Flow 76 (2015): $212-222$. https://doi.org/10.1016/i.ijmultiphaseflow.2015.06.011 